\title{
Annealing Assisted Enhancement of Electrochemical Stability of Na-Preintercalated Bilayered Vanadium Oxide Electrodes in Na-ion Batteries
}

\author{
Mallory Clites ${ }^{\mathrm{a}}$, James L. Hart ${ }^{\mathrm{b}, \mathrm{c}}$, Mitra L. Taheri ${ }^{\mathrm{b}, \mathrm{c}}$, Ekaterina Pomerantseva $^{\mathrm{a} *}$
}

a - Materials Electrochemistry Group, Department of Materials Science and Engineering, Drexel University, Philadelphia, Pennsylvania 19104, United States

b - Dynamic Characterizations Group, Department of Materials Science and Engineering, Drexel University, Philadelphia, Pennsylvania 19104, United States

c - Department of Materials Science and Engineering, Johns Hopkins University, Baltimore, Maryland 21218, United States

*_Corresponding author email: ep423@drexel.edu

\section{SUPPORTING INFORMATION}

1. Scanning Electron Microscopy (SEM) Characterization of $\delta-\mathrm{Na}_{x} \mathrm{~V}_{2} \mathrm{O}_{5} \cdot n \mathrm{H}_{2} \mathrm{O}$ Nanobelts with Varying Post- Synthesis Treatments

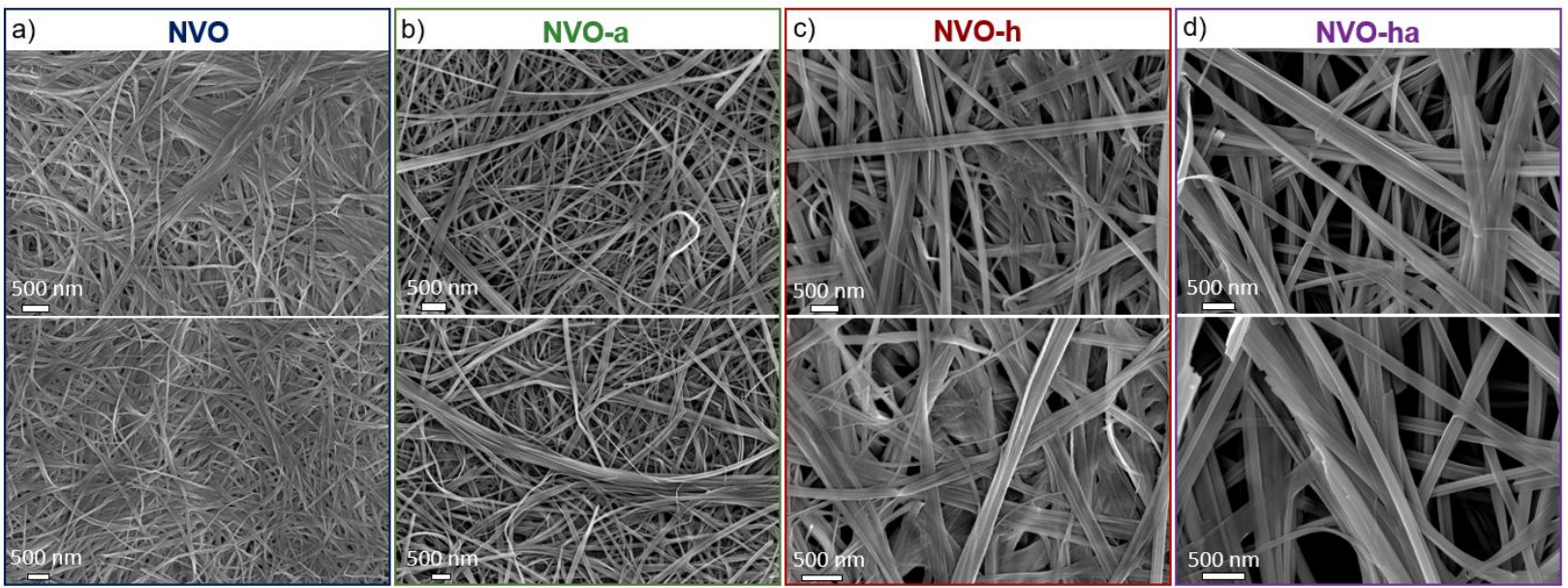

Figure S1. SEM images of $\delta-\mathrm{Na}_{\mathrm{x}} \mathrm{V}_{2} \mathrm{O}_{5} \cdot n \mathrm{H}_{2} \mathrm{O}$ nanobelts obtained after the following treatments of a precipitate formed in a sol-gel step: (a) aging only (NVO), (b) aging followed by vacuum annealing (NVO-a), (c) aging followed by hydrothermal treatment (NVO-h), (d) aging followed by hydrothermal treatment and vacuum annealing (NVO-ha). The images were taken at a $5 \mathrm{kV}$ at magnifications from 10 $\mathrm{kX}$ to $20 \mathrm{kX}$. 


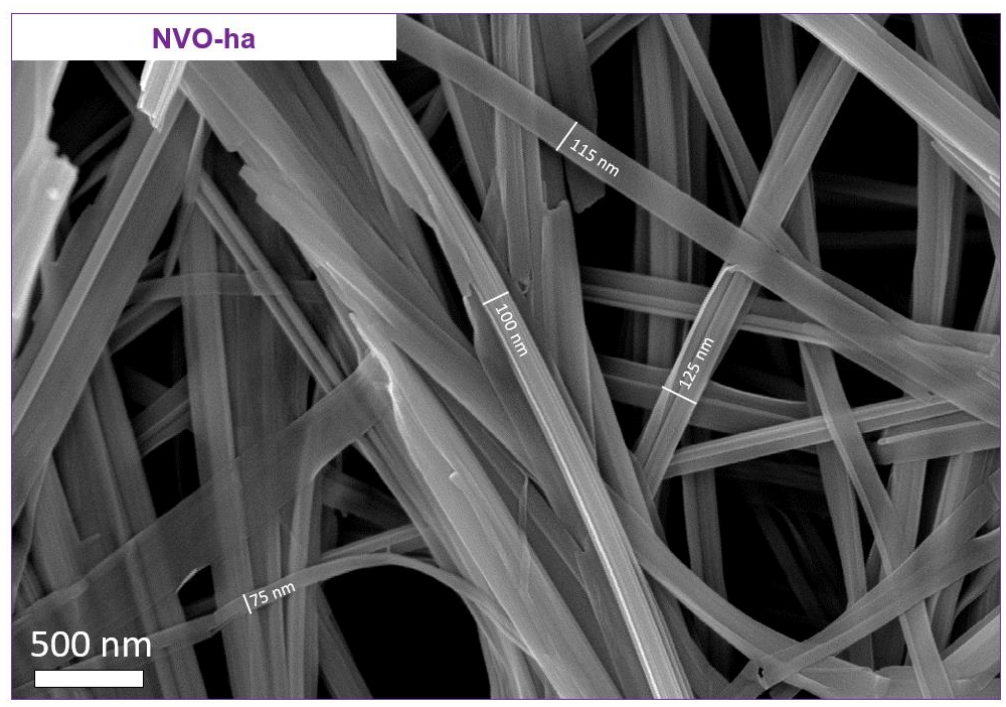

Figure S2. SEM image of NVO-ha nanobelts with several nanobelt thicknesses/widths measured. The image was taken at a $5 \mathrm{kV}$ at a magnification of $20 \mathrm{kX}$. 
2. Energy Dispersive X-ray (EDX) Spectroscopy of $\delta-\mathrm{Na}_{x} \mathrm{~V}_{2} \mathrm{O}_{5} \cdot n \mathrm{H}_{2} \mathrm{O}$ Nanobelts with Varying PostSynthesis Treatments
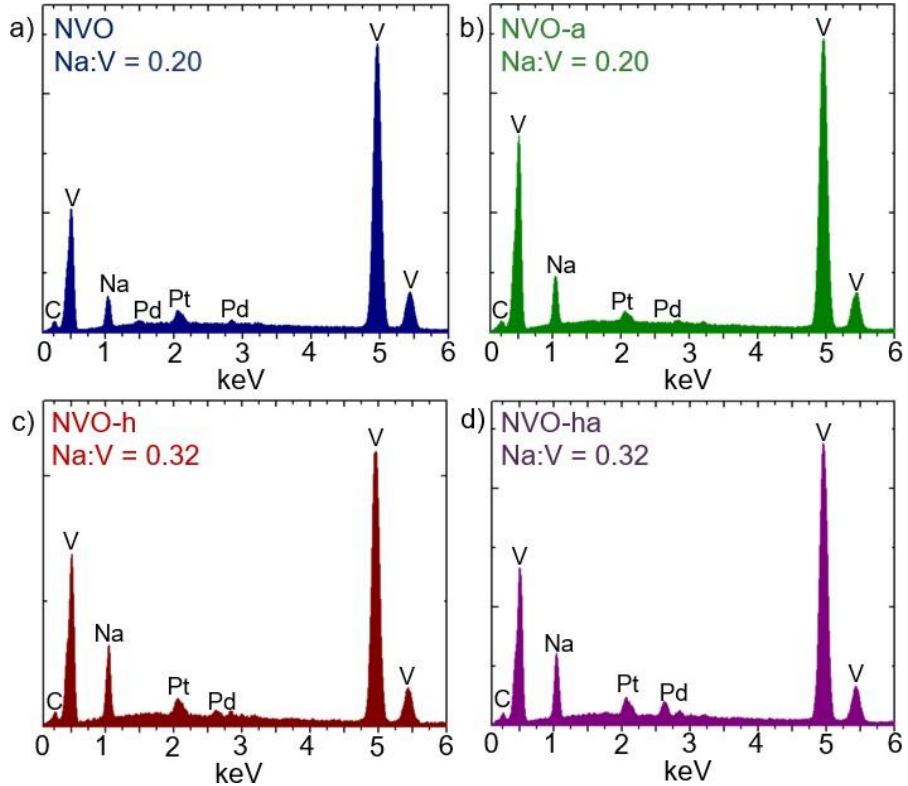

Figure S3. EDS spectra for the four NVO samples with varying post-synthesis treatments. Corresponding elements are labeled above each peak. EDS was run on $10 \mu \mathrm{m} \times 10 \mu \mathrm{m}$ areas at $15 \mathrm{kV}$. Na:V ratio was calculated for each sample using via quantification in the Oxford EDS software and was averaged using three spectra from three different sample areas.

Figure S3 shows respective EDX spectra for each synthesized sample. Peaks are labeled with the corresponding element and an $\mathrm{Na}: \mathrm{V}$ ratio is given in the inset. As all samples were sputter coated prior to SEM and EDX analysis, platinum (Pt) and palladium (Pd) peaks are present in the spectra. Additionally, a carbon (C) peak is present in all samples which is likely due to the presence of carbon tape beneath each sample for mounting purposes. The absence of chlorine peaks $(\mathrm{Cl})$ in the EDX spectra of all samples confirms that all unreacted salt was removed upon washing and filtering of the samples. Therefore, all sodium $(\mathrm{Na})$ content is considered to be preintercalated $\mathrm{Na}^{+}$ions within the bilayered $\delta-\mathrm{Na}_{\mathrm{x}} \mathrm{V}_{2} \mathrm{O}_{5} \cdot \mathrm{nH}_{2} \mathrm{O}$ structure. From EDX spectra and calculated Na: $\mathrm{V}$ ratios, it can be determined that the hydrothermally treated samples (NVO-h and NVO-ha) have higher $\mathrm{Na}^{+}$ion content than other two samples (NVO and $\mathrm{NVO}-\mathrm{a})$. This higher $\mathrm{Na}^{+}$ion content is achieved through the incorporation of $\mathrm{NaCl}$ into solution used in hydrothermal treatment. 
3. Thermogravimetric Analysis of the Aged and Hydrothermally Treated $\delta-\mathrm{Na}_{x} \mathrm{~V}_{2} \mathrm{O}_{5} \cdot n \mathrm{H}_{2} \mathrm{O}$ Nanobelts (Sample NVO-h)

Figure S4 shows the weight loss curve of the NVO-h sample heated from $25^{\circ}$ to $1000^{\circ} \mathrm{C}$ in air. The four regions of weight loss are marked and the corresponding reactions for these regions are given below.

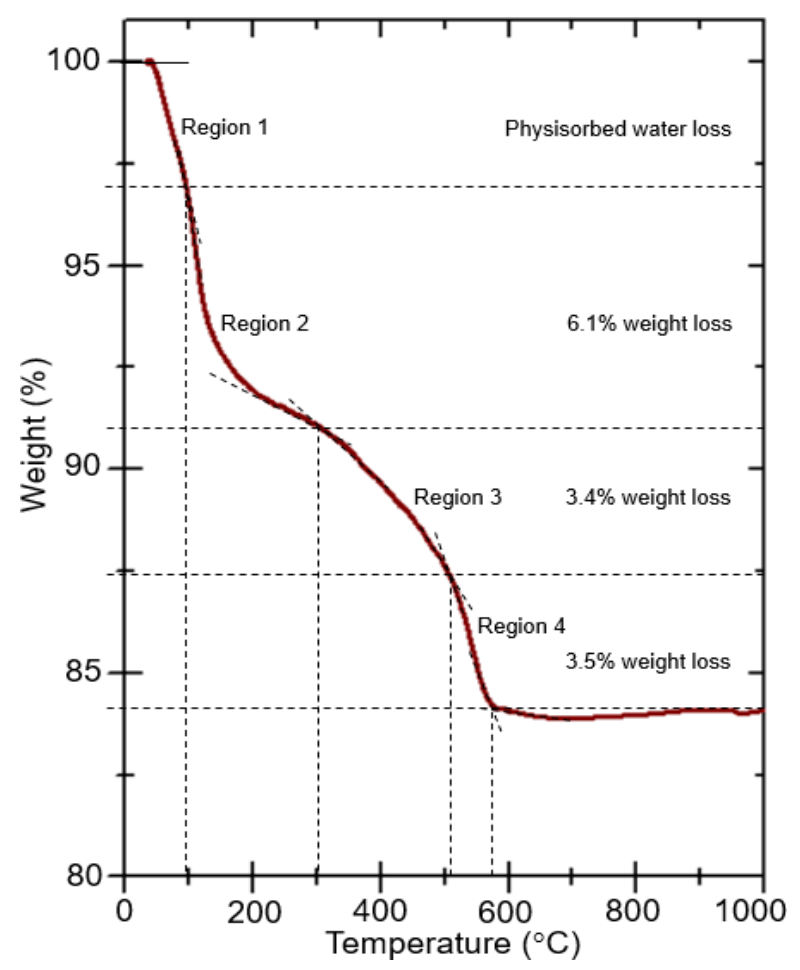

Figure S4. TGA curves of the NVO-ha phase from $0-1000^{\circ} \mathrm{C}$ with all regions of weight loss. Reactions for all weight loss regions are given below.

Region 1 - Physisorbed water loss:

$2.7 \%$ weight loss

Region 2 - Loss of the interlayer water without phase transformation:

$\delta-\mathrm{Na}_{0.64} \mathrm{~V}_{2} \mathrm{O}_{5} \cdot 1.2 \mathrm{H}_{2} \mathrm{O} \rightarrow \delta-\mathrm{Na}_{0.64} \mathrm{~V}_{2} \mathrm{O}_{5} \cdot 0.4 \mathrm{H}_{2} \mathrm{O}+0.8 \mathrm{H}_{2} \mathrm{O}$

$6.1 \%$ weight loss

Region 3 - Loss of the interlayer water accompanying the $\delta \rightarrow \beta$ phase transformation:

$\delta-\mathrm{Na}_{0.64} \mathrm{~V}_{2} \mathrm{O}_{5} \cdot 0.4 \mathrm{H}_{2} \mathrm{O} \rightarrow \beta-\mathrm{Na}_{0.64} \mathrm{~V}_{2} \mathrm{O}_{5}+0.4 \mathrm{H}_{2} \mathrm{O}$

$3.4 \%$ weight loss

Region 4 --Unidentified weight loss accompanying $\beta \rightarrow \mathrm{NaV}_{6} \mathrm{O}_{15}$ phasetransformation:

$\beta-\mathrm{Na}_{0.64} \mathrm{~V}_{2} \mathrm{O}_{5} \rightarrow \mathrm{NaV}_{6} \mathrm{O}_{15}+(\mathrm{X})$

$3.5 \%$ weight loss 


\section{X-ray Photoelectron Spectroscopy}

X-ray photoelectron spectroscopy (XPS) measurements were carried out to analyze the valence state of synthesized NVO, NVO-a, NVO-h, and NVO-ha samples. The spectra were recorded using a Physical Electronics PHI VersaProbe 5000 equipped with a monochromatic Al Ka radiation $(4,4867.7 \mathrm{eV})$.

XPS is a quantitative technique that can be used to characterize the composition and average oxidation state of the $\mathrm{V}$ atoms present in the synthesized samples. It is important to note that XPS is a surface-based quantitative technique. Therefore, the apparent valence state in these samples may differ from the bulk of the sample from the surface which was measured
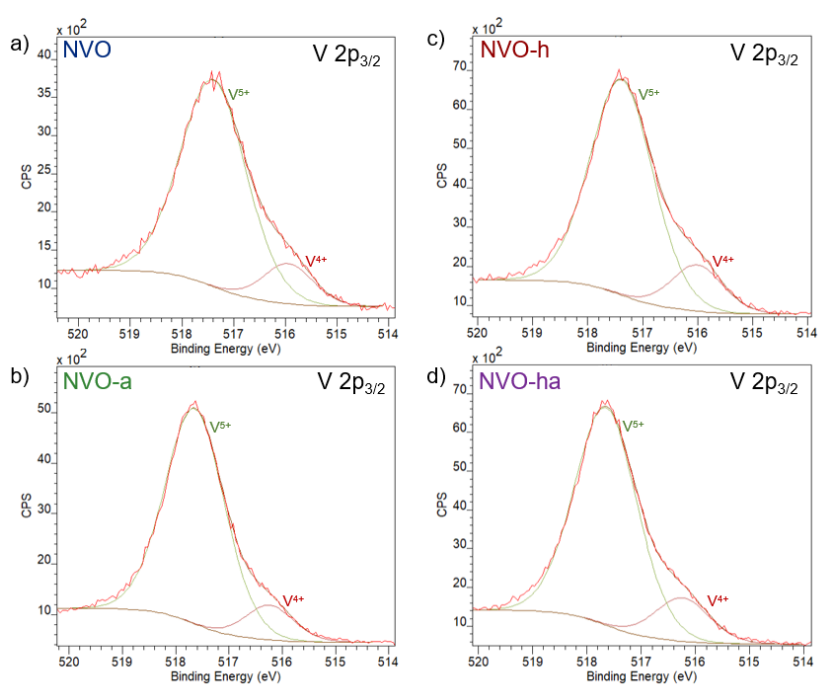

Figure S5. XPS spectra of the V 2 $\mathrm{p}_{3 / 2}$ core level for each of the synthesized samples.

Figure S5 shows the V 2 $\mathrm{p}_{3 / 2}$ core level binding energy region which reveals that all four samples exhibit mixed $\mathrm{V}^{5+}$ and $\mathrm{V}^{4+}$ valence states. The present of each valence state is given in Table $\mathrm{S} 1$.

Table S1. Percent of total signal observed that corresponds to each V valence state $\left(\mathrm{V}^{5+}\right.$ and $\left.\mathrm{V}^{4+}\right)$ determined from fitting XPS spectra.

\begin{tabular}{|c|c|c|c|}
\hline & $\mathrm{V}^{5+}$ & $\mathrm{V}^{4+}$ & Average oxidation state \\
\hline NVO & $87.2 \%$ & $12.8 \%$ & 4.872 \\
\hline NVO-a & $88.5 \%$ & $11.5 \%$ & 4.885 \\
\hline NVO-h & $85.1 \%$ & $14.9 \%$ & 4.851 \\
\hline NVO-ha & $85.2 \%$ & $14.8 \%$ & 4.852 \\
\hline
\end{tabular}

The results shown in Table $\mathrm{S} 1$ demonstrate that for samples with higher $\mathrm{Na}^{+}$ion content (NVO-h and NVO-ha) show some slight increase in the $\mathrm{V}^{4+}$ valence state. This is in agreement with preintercalated $\mathrm{Na}^{+}$ions causing the reduction of layered vanadium atoms from a $\mathrm{V}^{5+}$ to $\mathrm{V}^{4+}$ state for charge balance. Though an increase in the $\mathrm{V}^{4+}$ valence state is seen after hydrothermal treatment, the average oxidation state for all four samples are approximately the same and are within the range of $4.85-4.89$. This result suggests that despite a slight increase in $\mathrm{Na}^{+}$ion content upon hydrothermal treatment, the average oxidation state does not significantly change for these samples. 